\title{
Integration of GIS and F-Hydra Model for Aquifer Vulnerability Monitoring in the Afram Plains, Ghana
}

\author{
Asante Agyare ${ }^{* * \#, ~ A m o s ~ T i e r e y a n g n ~ K a b o-B a h 2 ~}{ }^{*}$, Bernard Trumah Bayel1*, \\ Abubakarr Sulaiman Jalloh ${ }^{{ }^{*}}$
}

${ }^{1}$ Department of Environmental Science and Engineering, Suzhou University of Science and Technology, Suzhou, China ${ }^{2}$ Department of Energy and Environmental Engineering, University of Energy and Natural Resources, Sunyani, Ghana Email: "asanteagyare@post.usts.edu.cn, "nasanteagyare@gmail.com, amos.kabobah@uenr.edu.gh,bbayeltrumah@gmail.com, abusjalloh@gmail.com

How to cite this paper: Agyare, A., Kabo-Bah, A. T., Bayel, B. T., \& Jalloh, A. S. (2021). Integration of GIS and F-Hydra Model for Aquifer Vulnerability Monitoring in the Afram Plains, Ghana. Journal of Geoscience and Environment Protection, 9, 222-248.

https://doi.org/10.4236/gep.2021.93014

Received: January 25, 2021

Accepted: March 27, 2021

Published: March 30, 2021

Copyright $\odot 2021$ by author(s) and Scientific Research Publishing Inc. This work is licensed under the Creative Commons Attribution International License (CC BY 4.0).

http://creativecommons.org/licenses/by/4.0/

\begin{abstract}
Aquifer vulnerability is a critical issue across the entire globe due to the depletion of groundwater and escalation of pollution levels, which poses a detrimental effect on the natural environment. To ascertain this contamination risk, an extensive study has been conducted to assess the aquifer vulnerability by using the F-hydra model. This paper presents the vulnerability technique for the theory and application of flow accumulation, land-use and hydraulic conductivity. The model was applied to a shallow aquifer in eastern Ghana's Volta River Basin, with the results being compared to the standardised DRASTIC model. The model follows the aquifer vulnerability assessment concept of the source pathway receptor where flow accumulation represents the ponding areas with downward percolation of contaminant to the water table, land-use represents the human activities at the land surface, and hydraulic conductivity represents the driving force leading to the movement of contaminant. The results reveal that the moderate vulnerability region covers $51.55 \%\left(2598.12 \mathrm{~km}^{2}\right)$ of the entire area. The high and low vulnerability regions cover a significant percentage of the area $1.13 \%\left(56.52 \mathrm{~km}^{2}\right)$ and $47.32 \%$ $\left(2384.93 \mathrm{~km}^{2}\right)$, respectively. The final vulnerability index was largely influenced by the removal of the hydraulic conductivity and land-use parameters. The model was validated with nitrate concentration in drilled wells in the study area. The maps produced in this study could be utilised as a guide to vulnerability by policymakers, groundwater manager and planners aimed at preserving the integrity of this vulnerable resource.
\end{abstract}




\section{Keywords}

GIS, Vulnerability, Aquifer, Nitrate Contamination, Groundwater, Afram Plains

\section{Introduction}

All groundwater is vulnerable to pollution from surface activities. However, the degree of vulnerability is dependent on several factors. Of prime importance is the nature of the aquifer system, i.e., its ability to act as a potential water resource (Stournaras et al., 2011; Lv et al., 2021; Mutiara et al., 2021; Xiang et al., 2021). In every community, water plays an important role. In addition to the fact that it is essential for life, groundwater facilitates a wide variety of ecological systems and contributes to the growth of the economy and recreational activities (Anornu et al., 2012; Egbi et al., 2019; Chakraei et al., 2021; Meran et al., 2021; Shen, 2021; Wang et al., 2021). Groundwater has been regarded as an essential and reliable resource for a water supply because of its generally low vulnerability to contamination in contrast with surface water and its capacity for storage (US EPA, 1985; Akter \& Ahmed, 2021; Lv et al., 2021). One classical example is the Nubian Sandstone water and its area coverage of about 2 million $\mathrm{km}^{2}$. This aquifer is a vital water resource for groundwater level and therefore sustainable development plans are needed to protect these vulnerable resources (Nageswara Rao \& Narendra, 2006).

Groundwater has a major contribution to agricultural, industrial, drinking, and other municipal uses, particularly in the region. Moreover, if it is also to be a dependable resource, capable to meet current and impending demand, then it has to be protected and managed effectively, not merely the quantity but also the quality. Thus, in defining sustainable water resources management plans at the regional or continental scale, assessments of groundwater resources and their associated impacts are strongly needed (Hasiniaina et al., 2010).

Aquifer vulnerability monitoring means to integrate comprehensive hydrogeological information into a structure useable to hydrogeologist, planners, geoscientists, the general public, decision and policy-makers (Liggett \& Talwar, 2009; Oke, 2015; Aslam et al., 2018; Hosseini \& Saremi, 2018; Fatema, 2020; Moreno et al., 2020; Oke \& Vermeulen, 2020; Song et al., 2020; Pollicino et al., 2021). The vulnerability method as a means of groundwater monitoring and management has been continually updated and validated since its first usage by Margat (1968). Some conventional methods used for aquifer vulnerability monitoring include DRASTIC (Depth-to-water table, Net Recharge, Aquifer media, Soil media, Topography, Impact of the vadose zone, Hydraulic Conductivity) (Aller et al., 1987), COP (Concentration of flow, Overlying layers, Precipitation) (Vías et al., 2006), EPIK (Epikarst, Protection cover, Infiltration, Karst network) (Doerfliger et al., 1999), AVI (Aquifer, Vulnerability, Index) (Stempvoort et al., 
1993), GOD (Groundwater occurrence, Overall aquifer class, Depth of groundwater) (Foster, 1987), PI (Protective cover, Infiltration) (Goldscheider et al., 2000), KAVI (Karst, Aquifer, Vulnerability, Index) (van Beynen et al., 2012), RTt (Rainfall, Travel time) (Oke, 2015), and many more. Several of these vulnerability techniques are tailored for specific aquifer systems, including the vulnerability of karst groundwater, whereas others discuss general protection of water supplies or the protection of a single source such as water wells.

A thorough understanding of the hydrogeological characteristics of aquifer systems concerning their environmental vulnerability is necessary to effectively exploit and protect groundwater against deterioration from its pristine state. Aquifers are not only characterised by hydraulic conductivity, but also by transmissivity (product of aquifer thickness and hydraulic conductivity) and diffusivity (ratio of storage coefficient and transmissivity). Others include soil composition or characteristics, existing climatic conditions, topography, mode and source of recharge, $\mathrm{pH}$, the resident time of water within the geological strata, the permeability of the soil cover and drainage area (Vrba \& Zaporozec, 1994; Olorunfemi et al., 1999; Ouedraogo et al., 2016; Shirazi et al., 2012; Shirazi et al., 2013).

The culmination of unregulated urbanization and industrialisation (as evident in most developing countries) compromise the pristine quality of several urban groundwater resources. While assessing the degree of vulnerability of aquifers and their protection from pollution, it is essential to comprehend the intrinsic property and hydrogeological characteristics. The aforementioned properties rely on the vulnerability of the aquifer system to natural or human impacts (Vrba \& Zaporozec, 1994).

Groundwater protection requires extensive information on aquifer vulnerability, notably mapping intrinsic properties of aquifers to pollution. For certain scenarios, a comprehensive vulnerability evaluation of the actual quantitative and qualitative status of a particular aquifer system is not feasible. This is attributable to inadequate knowledge for aquifer monitoring or the complexity of the aquifer systems (Worrall \& Kolpin, 2003). Alternatively, aquifer vulnerability indices are established and mapped to indicate or predict the actual severity of human-induced deterioration in groundwater quantity and quality (Balaji et al., 2021; Li et al., 2021; Rani et al., 2021).

In data-limited regions, the issue of inadequate monitoring data is further exacerbated. Data limited regions are major regions with little or no documented scientific information for research applications (Oke \& Vermeulen, 2020). Major regions in the African continent lack extensive geohydrological data owing to a reduced government budget on data collection and management of information. Most models of aquifer vulnerability assessments are regarded to be inapplicable to many regions of the African continent at times. This is not due to the scientific basis of the model, but primarily because of data unavailability.

The Afram Plains in the south-eastern region of Ghana's Volta River Basin, one of the Lower Voltaian sedimentary basins of West Africa (see Figure 1) is 


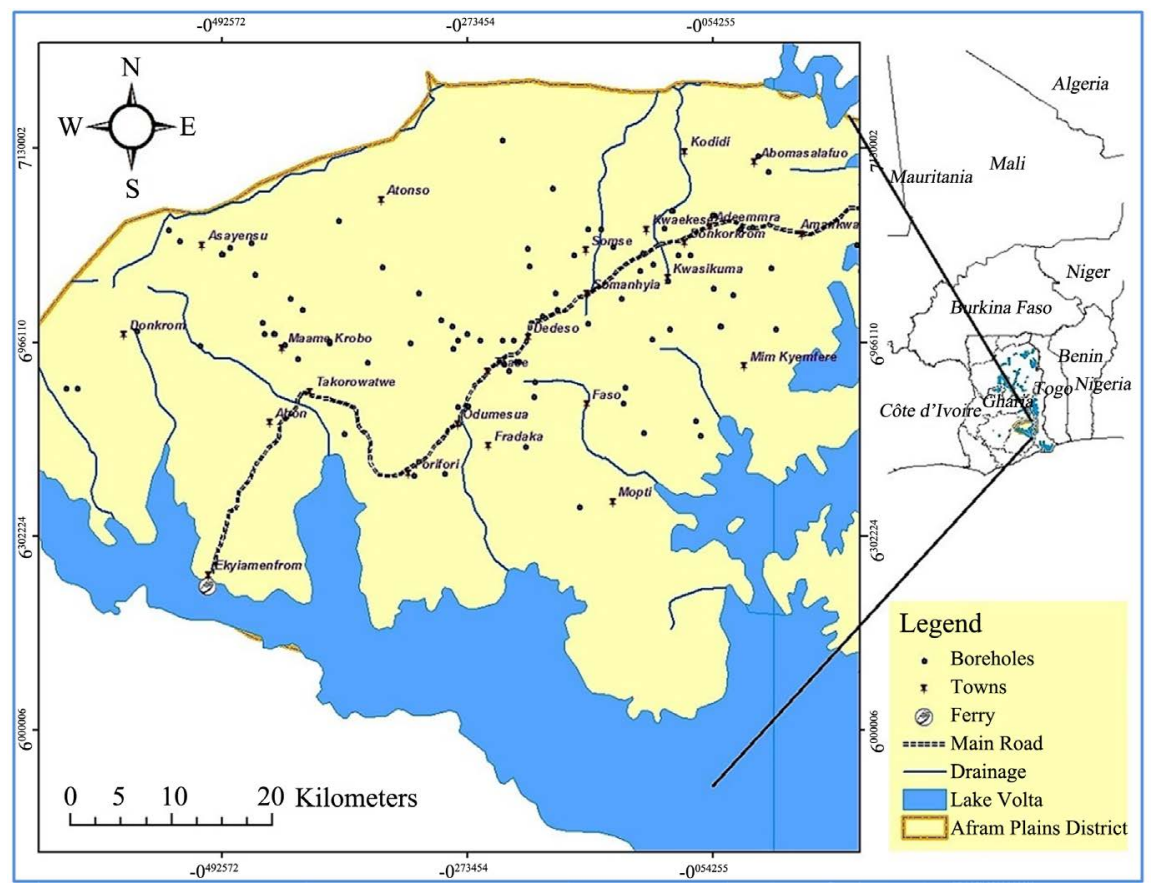

Figure 1. Study area map of Afram Plains, Ghana. Source: Agyare et al. (2017).

affected by the challenges of limited comprehensive hydrogeological data. Groundwater occurrence in the basin is found in a confined and unconfined state, depending on the sedimentary rock depositions that host the aquifer. The aquifers in the Afram Plains have also been tagged risky by Davies (2002), which is attributed to the extensive application of fertilizers and pesticides from the agricultural farmlands occupying about $70 \%$ of the entire landmass. Besides, other sources may include contaminants from septic or pit latrines, fuel stations, household and industrial waste disposal mainly from the developed areas (Agyare et al., 2017). Assessing the aquifer vulnerability in the basin, specifically, the unconfined aquifers would require evaluating the contributing factors responsible for groundwater protection. A breakdown by Agyare et al. (2017), indicates that more than half of the populace use water from tube wells (boreholes) while the remaining access water from large diameter hand-dug wells.

As mentioned earlier, various models for assessing groundwater vulnerability have been proposed and can also be useful in evaluating the aquifer systems in Afram Plains. However, due to the heterogeneity and complex nature of the aquifers and their protective cover coupled with insufficient hydrogeological data, there is the need of proposing other simplified models with fewer data needs. Thus, one way to develop an easily applicable model is to reduce the number of parameters (Gogu et al., 2003). The simplified models will be targeting the intrinsic properties of the aquifer protective cover and depicted with vulnerability maps. Natural protection investigations above the aquifer are required to promote laws and policies regarding land-use practises preventing contamination of groundwater. The objective of this study is to evaluate the vulnerability of aquifer systems in the Afram Plains of Ghana and determine the relationship be- 
tween the aquifer vulnerability indices and on-ground nitrate concentrations.

\section{Materials and Methods}

\subsection{Site Description}

Afram Plains is located in the lower Volta River Basin in the Eastern Region of Ghana. It is sited between latitude $6.6080^{\circ}$ and $7.1300^{\circ}$ and longitude $-0.0542^{\circ}$ and $-0.4926^{\circ}$ (see Figure 1). The Afram Plains has a geographical area of 5446 $\mathrm{km}^{2}$, as the largest district in the region, with an undulating land surface ranging between 60 to $120 \mathrm{~m}$ above mean sea level. The area is bounded to the north by the Obosum River, to the east by the Volta Lake, and to the south-west and south by the Afram River (Agyare et al., 2017).

The average annual rainfall in the Afram Plains ranges between 1150 and 1650 $\mathrm{mm}$. However, the highest rainfall ever recorded in the Afram Plains occurred in the year 1986 with an annual maximum depth of $1832 \mathrm{~mm}$ and a minimum depth of $546 \mathrm{~mm}$, which also occurred in 1987. The wet season in the Afram Plains starts from April to October and the dry season from November to late March. Some water demands are met during the wettest rainy period from May to September. The climate within the year traverses between warm and hot with annual mean temperatures of about $36.6^{\circ} \mathrm{C}$ to $36.8^{\circ} \mathrm{C}$ which generally peaks up around February to late March before the start of the rainfall season. The relative humidity is generally between $70 \%$ to $80 \%$ throughout the year (Agyare et al., 2017).

The soil types found in the Afram Plains are plinthosols, fluvisols, regosols, lixisols, luvisols and leptosols. Lixisols are the most dominant soil type that is found in the area. The aquifer systems are characterized by semi-confined aquifers with low permeability and secondary permeability within fractured zones (Davies, 2002). The geologic formation in the north-eastern margin of the study area is mainly composed of massive coarse-grained conglomerates, sandstones and shales. The quartzitic sandstones cap the north-western and south-western margins. Also, the central part of the study area is underlain by cross-bedded yellowish-white, greyish-purple and red quartzitic medium-grained sandstones, fine-grained sandstones, siltstones and conglomerates. The south-eastern portion is underlain by cross-bedded dark greyish purple and reddish-brown medium-to-fine grained sandstones with interbedded thin gravel bands as illustrated in Figure 2.

\subsection{Data Acquisition}

A GIS spatial database was constructed for the hydraulic conductivity, land-use and aquifer recharge of the study area. All the data was processed using ArcGIS $10.6^{\mathrm{TM}}$. Besides, spatial data possess different spatial resolutions, hence, the data layers were resampled to fit the recommended resolution with a scale of 1:600,000. Thus, $0.5 \mathrm{~km} \times 0.5 \mathrm{~km}$ resolution was selected for this study.

Data acquisition in Ghana is a great concern in Ghana as the required data is 


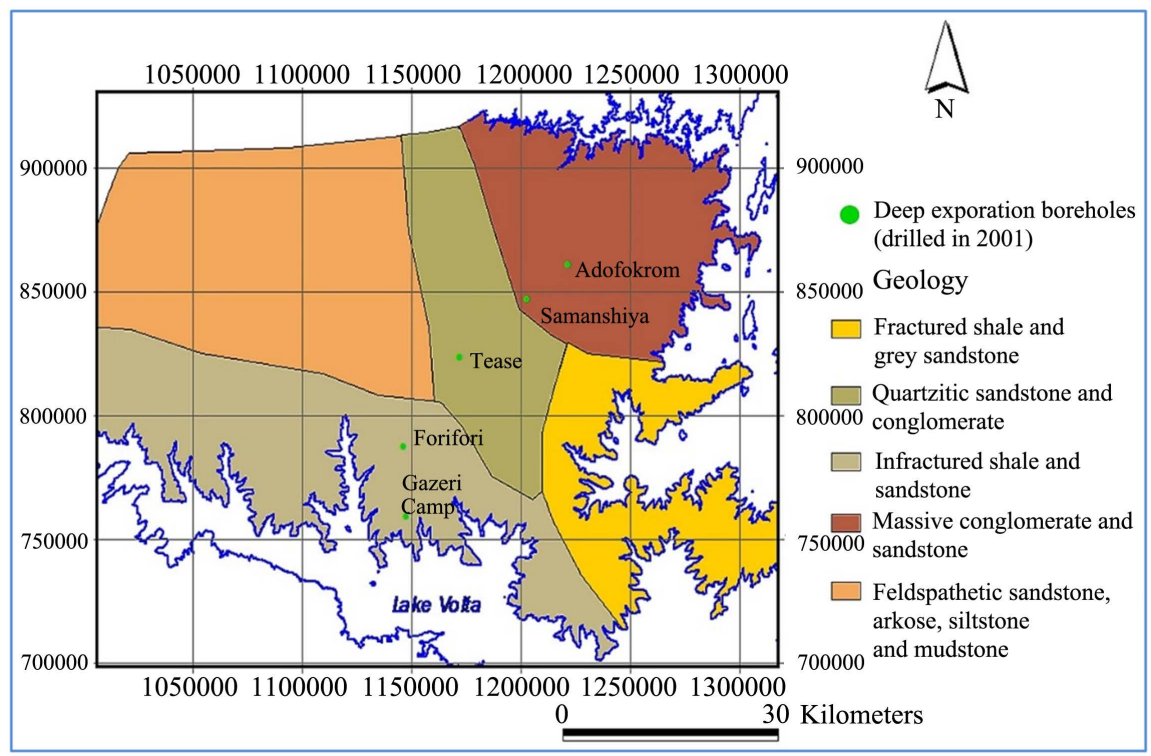

Figure 2. Geological formation map of Afram Plains, Ghana. Source: Davies (2002).

not readily accessible by the public. Thus, the data were derived from both primary and secondary sources including field works, literature reviews and laboratory analyses for hydro-chemical parameters. The methodology deployed in the generation of the maps is summarised in Figure 3.

\subsection{Groundwater Hydrogeochemical Characterisation}

\subsubsection{Sampling and Experimental Analysis}

The hydrogeochemical characterisations of groundwater environments, in both time and space, are essential for understanding the variability in terms of the physical and chemical characteristics of groundwater. The chemical composition of groundwater is essential for assessing the groundwater quality for vulnerability purposes. Water rock contact, mode of recharge, and human impact are only a few of the factors that influence the chemical characteristics of groundwater (Chilton, 2006; Robins et al., 2007; van Beynen et al., 2012; Erostate et al., 2018; Jaunat et al., 2019).

Groundwater sampling was conducted from March 2020 to April 2020. This enabled groundwater samples to be collected in both dry and wet seasons, which is significant for groundwater elemental concentration monitoring. The collected samples include shallow unconfined borehole and hand-dug wells which are the prime targets for this study. The unfiltered water samples were collected in sterilised $100 \mathrm{~mL}$ plastic bottles per each site using a bailer and transported in a refrigerated box to the laboratory between $1^{\circ} \mathrm{C}$ and $9^{\circ} \mathrm{C}$ before analysis. The wells sampled for water quality analysis and each site visited in the study area are shown in Figure 4.

\subsubsection{Hydro-Chemical Data Collection}

Water samples were collected in $500 \mathrm{~mL}$ bottles, unpreserved, unfiltered, and stored below $9^{\circ} \mathrm{C}$ for anion determination. Physico-chemical properties such as 


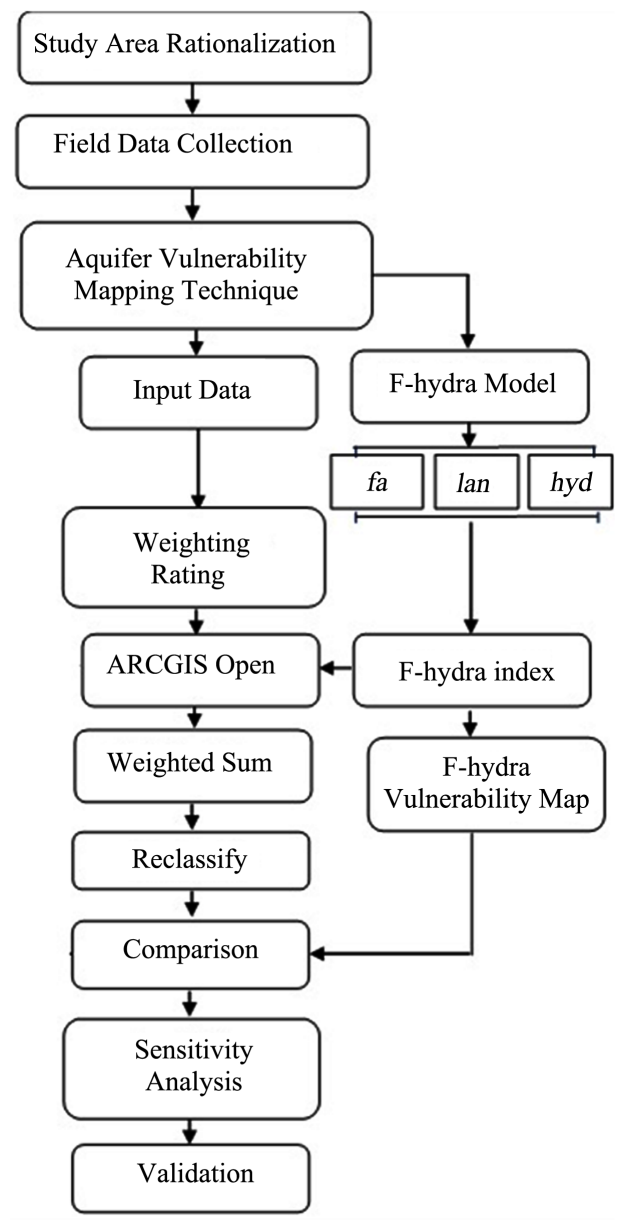

Figure 3. The methodology used to generate the vulnerability map.

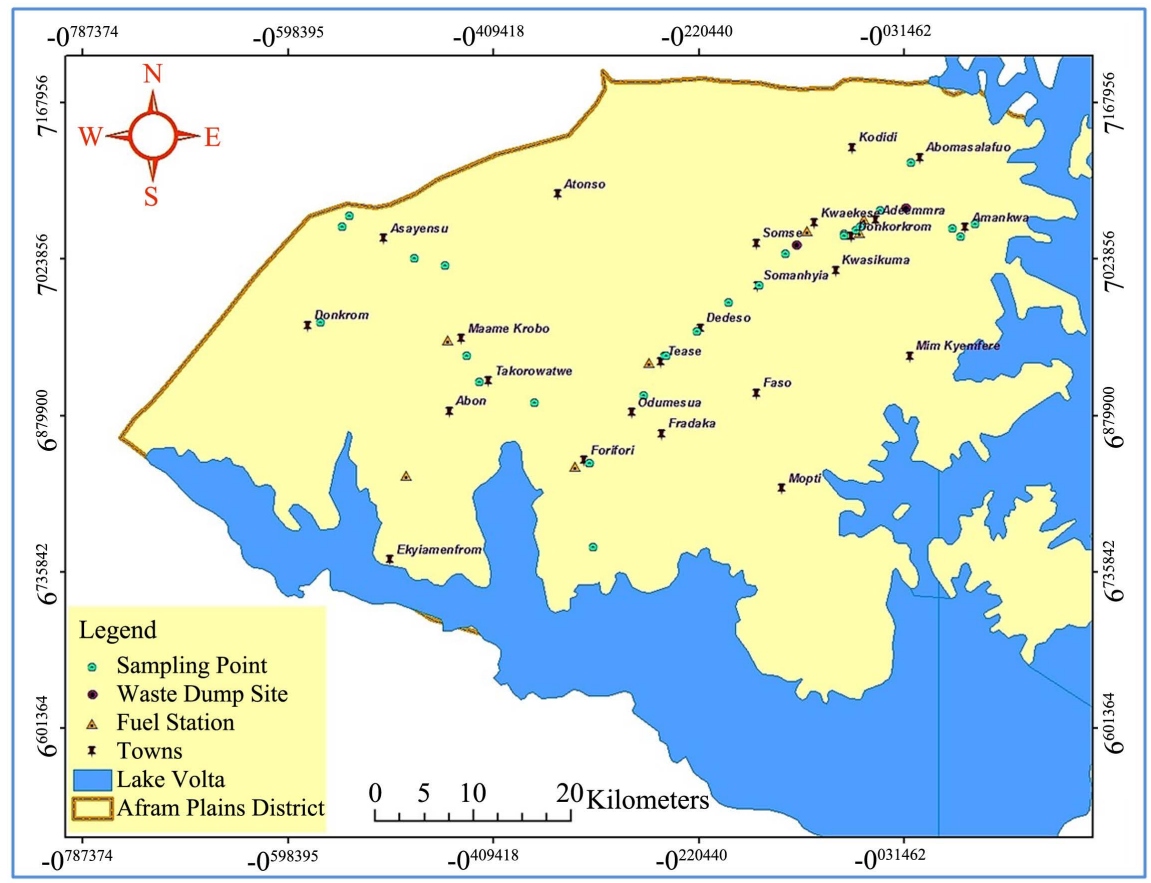

Figure 4. The location wells sampled for water quality analysis. 
total dissolved solids (TDS), $\mathrm{pH}$, dissolved oxygen were determined in situ using the YSI MultiLab meter (model EcoSense pH1000A). Ion chromatography (IC) was deployed to analyse for anions. Nitrate was measured after chromatography separation using conductivity detectors.

\section{The F-Hydra Model}

The subjective vulnerability model that was developed to address this gap is the F-hydra model. This model is focused on the diffuse recharge through a specified soil thickness with the assumption of precipitation as the driving mechanism in the vertical infiltration and subsequent percolation that replenishes the groundwater. The F-hydra model employs the objective as well as the subjective based vulnerability models. The F-hydra model was developed by Kabo-bah et al. (2014), which considers 3 core parameters as critical in the determination of the extent of vulnerability of the aquifer to contamination. The main condition in the use of the F-hydra model is to understand the basic parameters, namely flow accumulation ( fa), hydraulic conductivity ( $h y d)$, and landcover (lan).

The F-hydra model stands on the basis that the amount of precipitation infiltration and land-use activities at the surface must be known, and the dissolved solute contaminants in the infiltrating water have the same mobility rate as water. The contributing parameters are assigned a rating of 1 to 10 based on a characteristic range of values. The assigned weights vary from 30 to 40, whereas the highest weight denotes the most critical parameter. The total summation of the product of the ratings and weights of the respective parameters gives the vulnerability index. Table 1 and Table 2 presents the data required for the model and the assigned weights for each parameter, respectively. Equation (1) shows an addition formula of the F-hydra vulnerability index expressed as a percentage.

$$
V_{\text {in }}=R_{f a} W_{f a}+R_{\text {hyd }} W_{\text {hyd }}+R_{\text {lan }} W_{\text {lan }}
$$

Table 1. Data sources required for the F-hydra model.

\begin{tabular}{|c|c|}
\hline Parameter & Data Required \\
\hline Flow accumulation ( $\mathrm{fa}$ ) & $\begin{array}{l}\text { National Aeronautic Space Administration SRTM } 90 \text { m } \\
\text { resolution DEM. }\end{array}$ \\
\hline Hydraulic conductivity ( $h y d$ ) & $\begin{array}{l}\text { Global Hydrogeology Maps (GLYMPS) of permeability and } \\
\text { porosity developed by Gleeson et al. (2014). }\end{array}$ \\
\hline Landcover (lan) & 300 m MODIS-based landcover climatology (2010-2020). \\
\hline
\end{tabular}

Table 2. Assigned weights for F-hydra parameters.

\begin{tabular}{cc}
\hline Parameter & Weight, $W(\%)$ \\
\hline Flow accumulation $(f a)$ & 30 \\
Hydraulic conductivity $($ hyd $)$ & 40 \\
Landcover $($ lan $)$ & 30 \\
\hline
\end{tabular}


where $V_{i n}$, F-hydra vulnerability index; $R$ and $W$, Rating and Weighting for each parameter, respectively.

The concept of the model was originally defined by the European Groundwater Vulnerability Approach, origin-pathway-target (Daly et al., 2002; European Commission COST Action 620, 2003). In general, the fa parameter is used to define the drainage pattern of terrain and provides information about the potential availability of groundwater recharge from rainfall. The hyd parameter is a function of the recharge rate, aquifer thickness, and the length of effective groundwater drainage, while the lan parameter, on the other hand, is a function of the soil type, rock formation and slope (Kabo-bah et al., 2014).

\subsection{Parameters Controlling Aquifer Vulnerability}

\subsubsection{Flow Accumulation Parameter}

Flow accumulation in principle is utilized to illustrate the drainage outline of any given terrain. The flow accumulation parameter was determined through a procedure using a Digital Elevation Model (DEM) ArcGIS software. DEM images were extracted from the National Aeronautics and Space Administration (NASA) and the United States Geological Survey (USGS) Landsat imageries. The elevation model was reprocessed from the Global Land Survey (GLS) collection. The GLS collection comprises imageries from TM, ETM+ and ALI sensors. GLS-DEM uses a $90 \mathrm{~m}$ resolution and covers $185 \mathrm{~km} \times 185 \mathrm{~km}$. The slope differs from the upper end of the study area and decreases towards the lake.

The ArcGIS software computes the expected flow paths from a given DEM using the rule that flow should be in the downward direction. The ArcGIS system computes the slope in each of the directions and determines the new flow direction as the steepest one as indicated in Step 1. The next step is the flow determination which is found just beneath the DEM visualization. First, the fill sink tool was executed to ensure that all areas in the DEM that obstruct flow are either levelled out or raised to facilitate smooth movement of water from one end to the other. The output map contains directions such as Southeast (SE), Southwest (SW) etc. This is indicated in Step 2 in Figure 5.

The next is the creation of the flow direction map. The flow direction tool is selected, and also by checking the steepest slope method as well as the parallel drainage correction algorithm. This is computed for all central pixel in input blocks of 3 by 3 pixels, and each time contrasting the value of the central pixel with the surrounding 8 neighbouring pixels as indicated as Step 3. The obtained map from the computation of the flow direction will automatically be used to derive the flow accumulation map of the terrain. The output map contains cumulative hydrologic flow values that signify the number of input pixels that contribute any water to the outlets (Step 4). The flow accumulation rating is presented in Figure 6 and Table 3.

\subsubsection{Hydraulic Conductivity Parameter}

This parameter measures permeability. It depends on the intrinsic permeability 


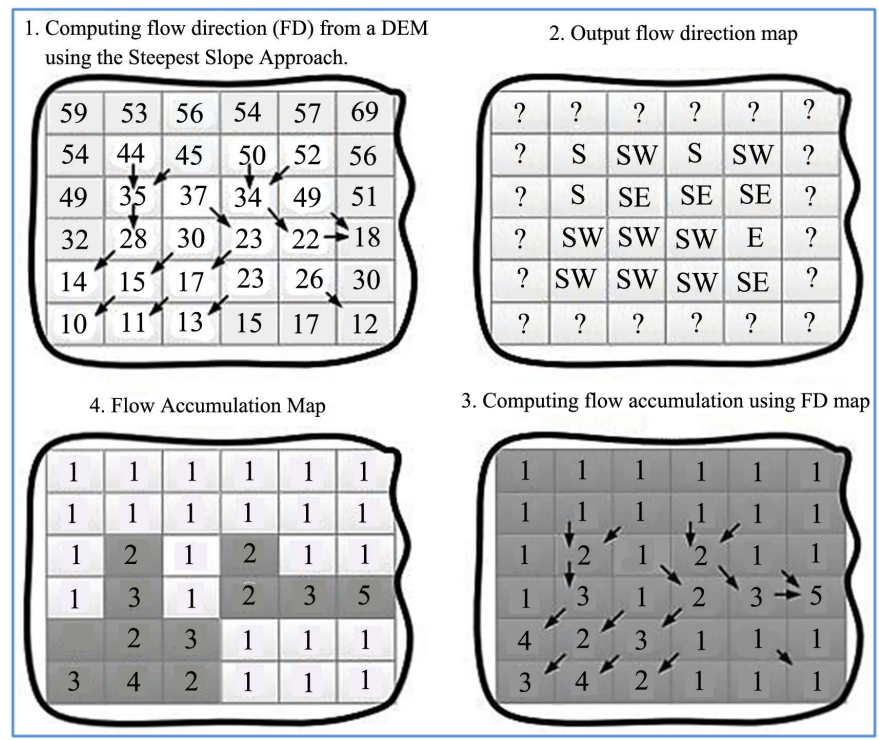

Figure 5. Procedure for deriving the flow accumulation map. Source: Kabo-bah et al. (2014).

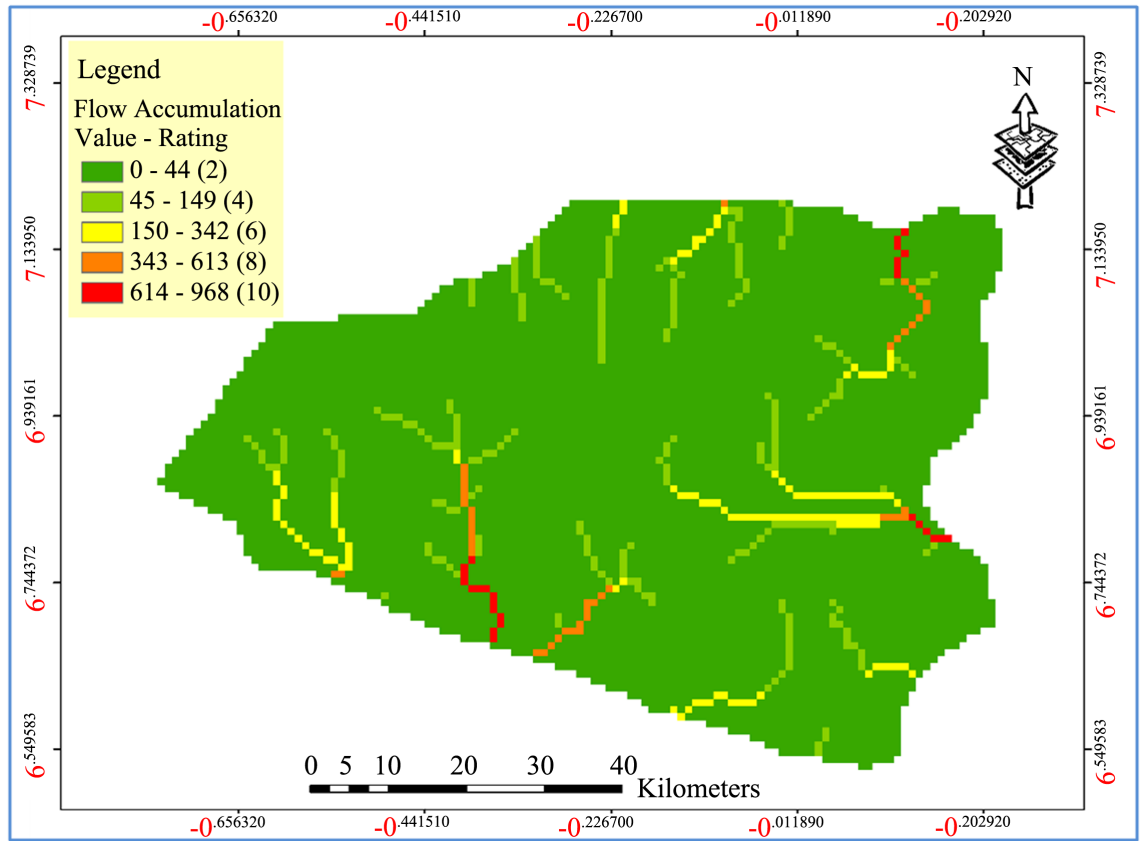

Figure 6. Flow accumulation rating map.

Table 3. Flow accumulation rating table.

\begin{tabular}{ccc}
\hline Range & Rating, $R_{f \mathrm{a}}$ & $(R \times W)_{f \mathrm{fa}}$ \\
\hline $0-44$ & 2 & 60 \\
$45-149$ & 4 & 120 \\
$150-342$ & 6 & 180 \\
$343-613$ & 8 & 240 \\
$614-968$ & 10 & 300 \\
\hline
\end{tabular}


of the material and the degree of saturation. This is a critical factor that controls the contaminant migration and dispersion from the injection point within the unsaturated zone through to the saturated zone. Therefore, the higher conductivity, the more susceptible the aquifer. The calculated hydraulic conductivity for the study area was evaluated for consistency with other literature estimates. In this study, the hydraulic conductivity was inferred from the global permeability map. The data were given in $\log$ permeability $(\log k)$. Since hydraulic conductivity is a critical parameter in assessing aquifer vulnerability, the permeability $(k)$ was converted into conductivity values using Equation (2).

$$
K=k \times \frac{g}{\mu}
$$

where: $K$, hydraulic conductivity $\left(\mathrm{m} / \mathrm{s}\right.$ or $\mathrm{m} /$ day); $\rho$, fluid density $\left(\mathrm{kg} / \mathrm{m}^{3}\right) ; g$, force of gravity $\left(\mathrm{m} / \mathrm{s}^{2}\right) ; \mu$, fluid viscosity $(\mathrm{kg} / \mathrm{m} \cdot \mathrm{s})$.

However, it was revealed that literature estimates of $0.01-0.05 \mathrm{~m} /$ day by Lutz et al. (2007). The estimates from Equation (2) vary between $0.01-0.03 \mathrm{~m} /$ day. For is well known, that estimating accurately the hydraulic conductivity is quite difficult, yet the overall consistency of this estimate was found to be satisfactory. The most prevalent value covering about $34 \%$ of the area $(R=6)$, followed by $35 \%$ of the area $(R=4)$ and the remaining $31 \%(R=2)$ as presented in Table 4 and Figure 7. Areas of vulnerability were identified by the rating index from 40 to 240 . Areas with high conductivity values of 0.0289 to $0.03617 \mathrm{~mm}$ /day are prone to contamination as compared to areas with low conductivity values of 0.0102 to $0.0169 \mathrm{~mm} /$ day.

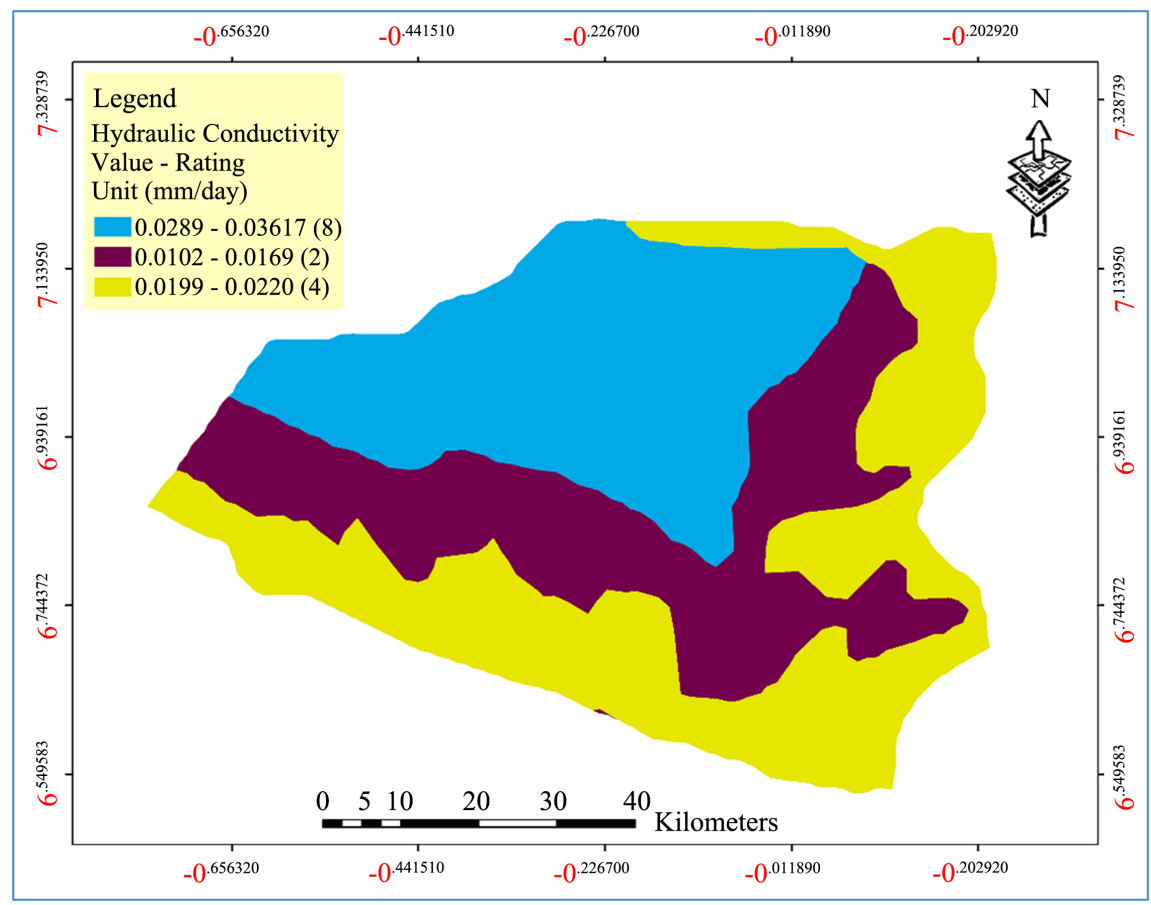

Figure 7. Hydraulic conductivity rating map. 
Table 4. Hydraulic conductivity rating table.

\begin{tabular}{ccc}
\hline Range & Rating, $\boldsymbol{R}_{\text {hyd }}$ & $\left(R \times W_{\text {hyd }}\right.$ \\
\hline$<0.0102$ & 1 & 40 \\
$0.0103-0.0169$ & 2 & 80 \\
$0.0170-0.0288$ & 4 & 160 \\
$0.0289-0.0367$ & 6 & 240 \\
\hline
\end{tabular}

\subsubsection{Landcover Parameter}

The landcover parameter reveals the change or modification to the natural environment as a result of the activities on the Earth surface. These activities may cause a detrimental effect on both the quality and quantity of the aquifer. The following are the definition of the various landcover classes identified as shown in Figure 8.

- Water bodies: This class represents the stream networks (Lake Volta and its tributaries), the reservoirs and any identifiable water bodies on the surface.

- Evergreen Forest: It characterizes a group of trees holding their leaves permanently throughout the year. The decrease of such forest in the study area is also significant probably due to deforestation.

- Shrublands: It characterizes vegetation dominated by shrubs including grasses, herbs, and geophytes.

- Grasslands: Represents all grasses, shrubs and all types of small vegetation.

- Croplands: These types of lands are mainly used for crop cultivation. The agricultural activities in the area are mainly rain-fed agriculture. Besides, some irrigated areas are identified and are all classified under croplands. Thus, one of the major non-point source pollutions of the aquifer is caused by nitrate in the agriculture areas. Hence, high contamination risk should be anticipated due to the intense agricultural activities and input such as fertilizer and pesticides.

In this study, 15 series of land-use were identified and re-grouped into 5 classes namely: water bodies $(R=3)$, evergreen broadleaf forest $(R=1)$, shrublands $(R=4)$, grasslands $(R=4)$ and croplands $(R=10)$ as illustrated in Figure 8. Subsequently, the weight and ratings assigned to the land-use parameter are presented in Table 5.

\subsection{Instance(s) of F-Hydra Model Application and Limitations}

The F-hydra model has not been applied widely in aquifer vulnerability studies. Kabo-bah et al. (2014), utilized this newly developed F-hydra index to evaluate the pollution potential of the Densu Basin. The results indicated that more than $65 \%$ of the entire landmass is highly susceptible to pollution once they occur while less than $2 \%$ of the total areas were classified as low.

Notwithstanding, the F-hydra as compared to other models has certain practical constraints. Several drawbacks of the F-hydra model include: 1) Lateral flow of contaminant in the saturated zone is not considered (Kabo-bah et al., 2014); 


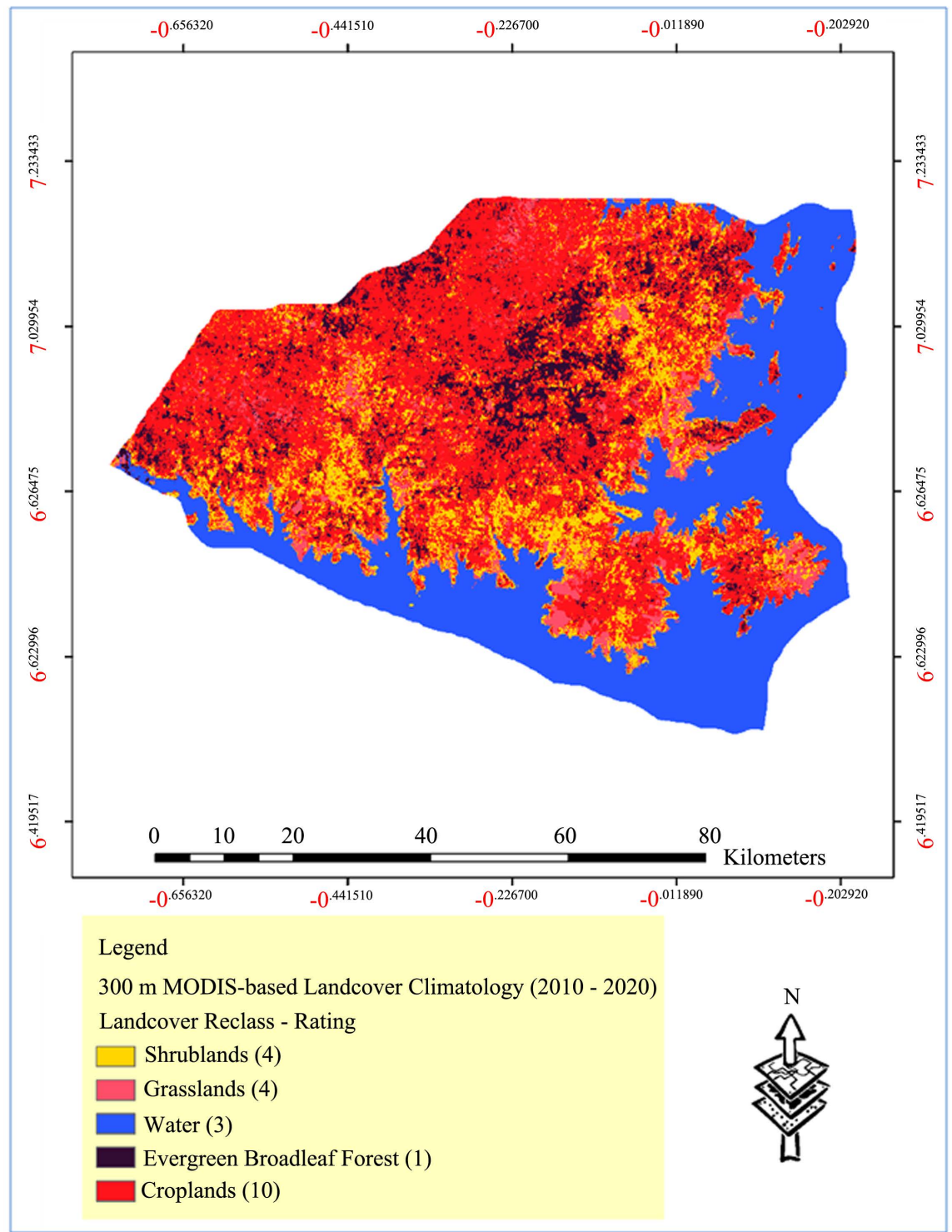

Figure 8. Landcover rating map.

Table 5. Landcover rating table.

\begin{tabular}{ccc}
\hline Classes & Rating, $R_{\text {lan }}$ & $(R \times W)_{\text {lan }}$ \\
\hline Evergreen broadleaf forest & 1 & 30 \\
Natural vegetation mosaic & 2 & 60 \\
Water & 3 & 90 \\
Shrub/Grasslands & 4 & 120 \\
Urban areas, dams & 5 & 150 \\
Waste treatment plant & 6 & 180 \\
Wetlands & 7 & 210 \\
Mangrove & 8 & 240 \\
Croplands & 10 & 300 \\
\hline
\end{tabular}


2) Complexity in updating maps (Gogu \& Dassargues, 2000); and; 3) Inaccurate in predicting the extent of pollution or vulnerability to some degree in the subsurface region (Kabo-bah et al., 2014).

\subsection{Sensitivity Analysis}

Sensitivity analysis presents a thorough detail on the influence of weights or ratings assigned to the individual parameters considered for the model (Krishna et al., 2015). There are 2 types of sensitivity analysis namely; single-parameter analysis and map removal sensitivity analysis. The single-parameter removal sensitivity analysis test points out the influence of each parameter on the final vulnerability index. Thus, the effective weight of each parameter can be estimated using Equation (3).

The second category represents the sensitivity of the final vulnerability map to the removal of one or more parameter map layers and determined using Equation (4). Before the analysed results, authors can ascertain that their assigned weight was accurate or there is a need for modification. Estimation of the variation index demonstrates the influence of each map layer on the overall vulnerability index when removed.

To assess the degree of variation created by removing one parameter, the variation index is calculated using Equation (5). Besides, this value solely depends on the weight assigned to the individual parameters. Several authors have applied sensitivity analysis to aquifer vulnerability evaluation (Rahman, 2008; Hasiniaina et al., 2010; Samake et al., 2011; Krishna et al., 2015; Tsoy, 2015; Ouedraogo et al., 2016; Balaji et al., 2021; Ghouili et al., 2021; Li et al., 2021; Pelekanos et al., 2021; Rokhshad et al., 2021).

$$
\begin{aligned}
& S_{i}=\left(\frac{\frac{V_{i}}{N}-\frac{V_{x i}}{n}}{V_{i}}\right) \times 100 \\
& W_{i}=\left(\frac{P_{r, i} \times P_{w, i}}{V_{i}}\right) \times 100 \\
& V_{a r}=\left(\frac{V_{i}-V_{x i}}{V_{i}}\right) \times 100
\end{aligned}
$$

where $S_{i}$ is the sensitivity index associated with the removal of one parameter map; $V_{i}$ and $V_{x i}$ are the unperturbed and perturbed vulnerability indices respectively; $i$ signifies the cell number; $N$ and $n$ signify the number of parameters used to compute $V_{i}$ and $V_{x i}, W_{i}$ signifies the effective weight; $P_{r, i}$ and $P_{w, i}$ are the rating and the weight of each parameter map layer respectively; $V_{i}$ refers to the overall vulnerability index; $V_{a r}$ is the variation index of the removal parameter map layer. Thus, the unperturbed vulnerability index is considered to be the overall vulnerability index obtained using all the 3 parameter map layers and the perturbed vulnerability index refers to the index calculated using fewer parameter map layers. 


\section{Results and Discussion}

\subsection{The F-Hydra Vulnerability Index}

The underlying principle of this study is that all aquifer systems are vulnerable to some extent. As a result, this present work aimed to evaluate the aquifer vulnerability to pollution in the Afram Plains District. To achieve this goal, the F-hydra model was applied for this evaluation and compared to the widely known DRASTIC model to ascertain the dependability of the results. The final F-hydra vulnerability map was produced by combining the 3 vital parameters. This was however after classification through numerical rating and creating a raster file from the numerical values. The F-hydra index was computed using Equation (1). The aquifer vulnerability index was sub-divided into 3 classes. These classes were: Low (140 - 420), Moderate (421 - 580), High (581 - 840). The vulnerability zones of the study area were obtained with the indication of indexes as illustrated in Figure 9.

$$
\begin{aligned}
\text { Min. vulerability index } & =\sum_{i=1}^{3} \text { rating }_{i} \times \text { weight }_{i} \\
& =(30 \times 1)+(30 \times 1)+(40 \times 2)=140 \\
\text { Max. vulerability index } & =\sum_{i=1}^{3} \text { rating }_{i} \times \text { weight }_{i} \\
& =(30 \times 10)+(30 \times 10)+(40 \times 6)=840
\end{aligned}
$$

The vulnerability obtained is low to moderate vulnerability, and this is according to the indication of indices. The percentages of the area covered under the various classes are $47.32 \%, 51.55 \%$ and $1.13 \%$ for low, moderate and high, respectively are presented in Table 6 . The vulnerability distribution of the study

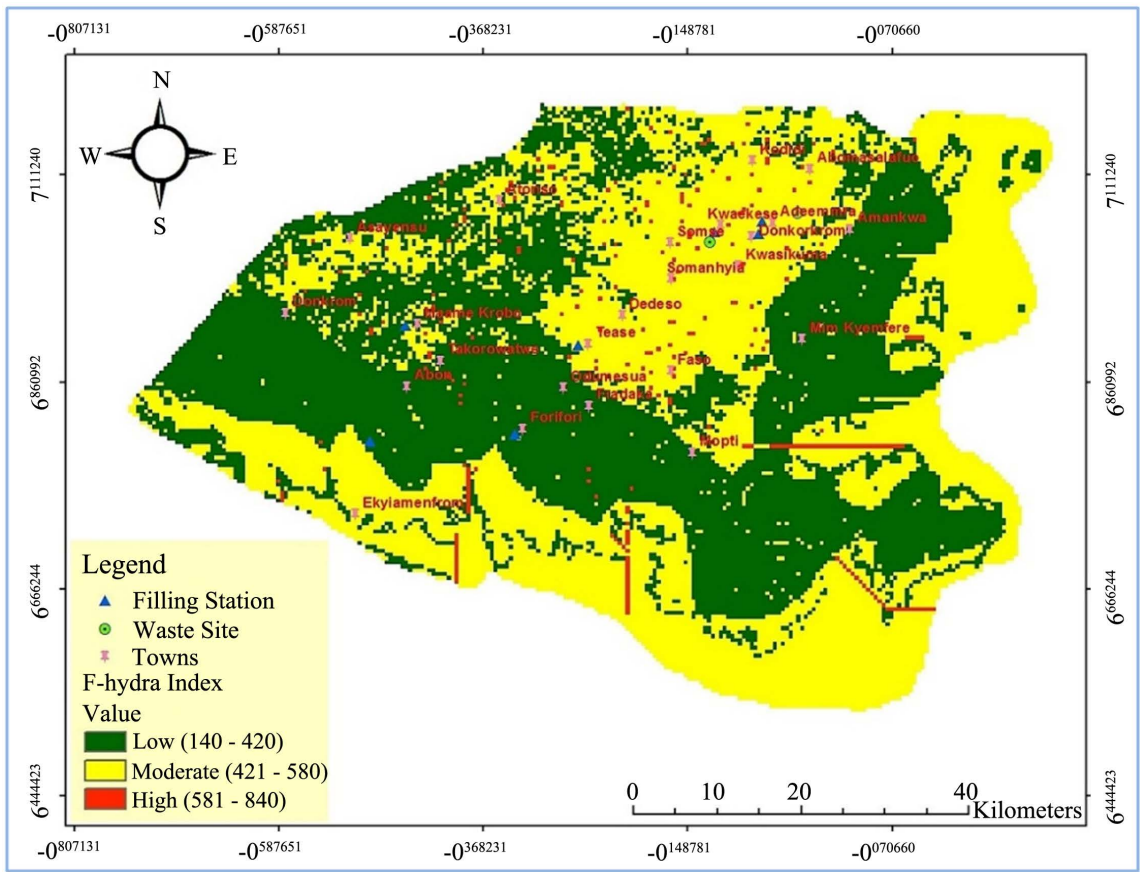

Figure 9. F-hydra vulnerability index map. 
Table 6. Classification of F-hydra index.

\begin{tabular}{cccc}
\hline F-hydra Index & Matrix & Area (\%) & Area $\left(\mathrm{km}^{2}\right)$ \\
\hline $140-420$ & L & 47.32 & 2384.93 \\
$421-580$ & M & 51.55 & 2598.12 \\
$581-840$ & H & 1.13 & 56.52 \\
\hline
\end{tabular}

L: Low; M: Moderate; H: High.

area shows low vulnerability in areas with low recharge and low hydraulic conductivity. This is due to geologic formation hosting the aquifer in these areas are composed of tertiary clay and clayey-sand deposits which are impermeable (Al-Adamat et al., 2003; Neukum \& Azzam, 2009; Al Hallaq \& Elaish, 2012).

The final F-hydra output map was compared with the DRASTIC output map of the study area developed by Agyare et al. (2017). The rationale behind this comparison is because DRASTIC model has been recognized as a standardised model that offers the user the ease to explain the vulnerability index from their expert knowledge based on the hydrogeological setting of the terrain (Gogu et al., 2003).

According to Figure 10, the DRASTIC index range between 71 and 197. The aquifer vulnerability derived was classified from low to high based on the indexes. The percentages of the area covered under the various classes are $20.71 \%$, $49.78 \%$ and $29.50 \%$ for low, moderate and high, respectively, as presented in Table 7. The distribution of the aquifer vulnerability by the DRASTIC model exhibits high vulnerability in regions with low topography, depth-to-water, and relatively high hydraulic conductivity, while the low vulnerability was mapped for regions having a high vadose thickness, high clayey content in soils and likely the lowest precipitation region of the basin (Agyare et al., 2017).

Comparatively, both models yielded different results in terms of percentages of the mapped zones (see Table 7). These differences are quite significant with exception of the moderate vulnerability class which can be argued off as minor. However, the F-hydra model mapped the central and eastern margins as moderately vulnerable whilst the DRASTIC model assessed the region as highly vulnerable. The difference between the moderate and high vulnerability in the DRASTIC map is greatly influenced by the depth-to-water table.

Obviously, the depth-to-water table parameter in the DRASTIC model determines whether a zone will be classed as moderate or high vulnerability. Nonetheless, this parameter is not incorporated in the F-hydra model for aquifer vulnerability assessment (Gogu et al., 2003; Gumma \& Pavelic, 2013). This could be the reason for the differences in the percentages of mapped zones, especially between the moderate and high vulnerability regions.

\subsection{Sensitivity Parameter Analysis}

A summary of the parameter relationship analysis for the F-hydra parameters is presented in Table 8. The result of the analysis reveals that the land-use 


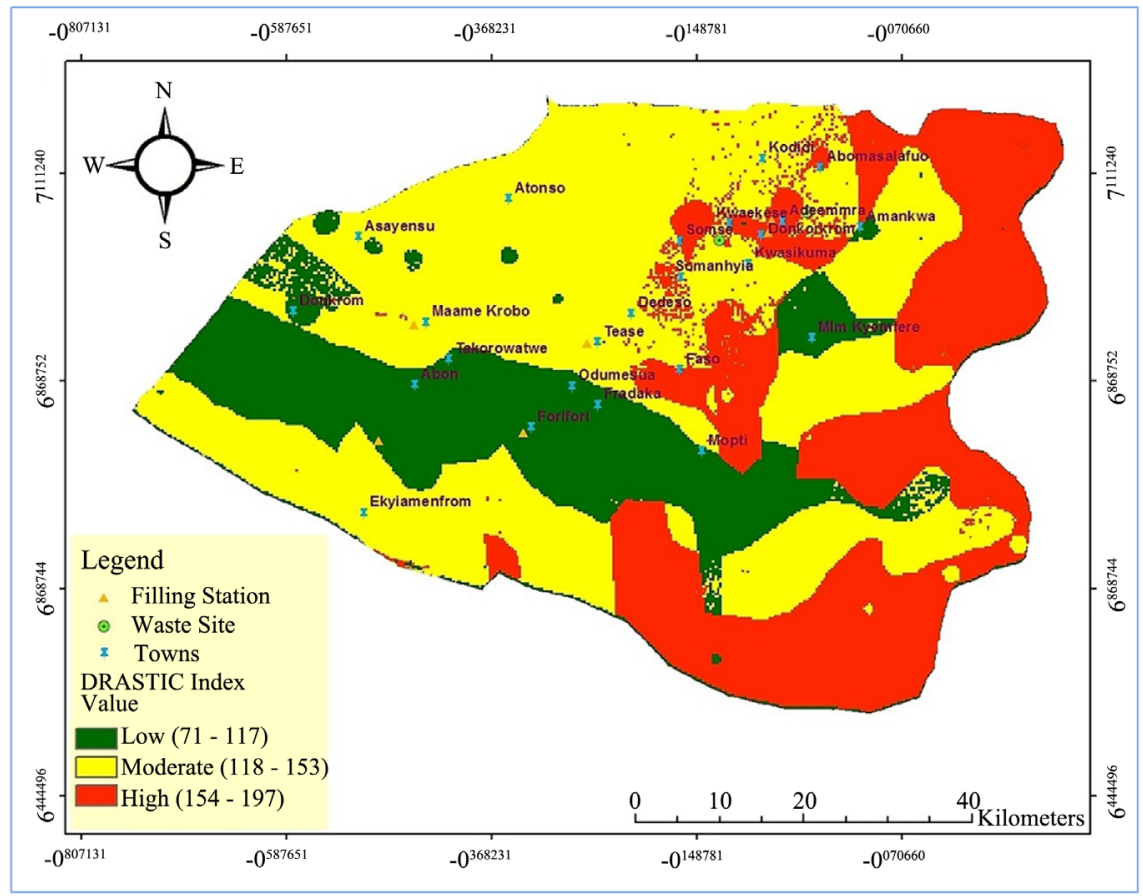

Figure 10. DRASTIC vulnerability index map. Source: Agyare et al. (2017).

Table 7. Classification matrices between DRASTIC and F-hydra Indexes.

\begin{tabular}{ccccc}
\hline Matrix & DRASTIC Index & Area (\%) & F-hydra Index & Area (\%) \\
\hline Low & $71-117$ & 20.72 & $140-420$ & 47.32 \\
Moderate & $118-153$ & 49.78 & $421-580$ & 51.55 \\
High & $154-197$ & 29.50 & $581-840$ & 1.13 \\
\hline
\end{tabular}

Table 8. Statistical summary of the F-hydra parameter.

\begin{tabular}{cccc}
\hline Parameter & fa & lan & hyd \\
\hline Minimum & 1.00 & 1.00 & 2.00 \\
Maximum & 10.00 & 10.00 & 6.00 \\
Mean & 5.12 & 5.15 & 4.24 \\
$\mathrm{SD}^{*}$ & 2.20 & 2.38 & 3.34 \\
$\mathrm{CV}^{*}(\%)$ & 46.21 & 51.89 & 65.23 \\
\hline
\end{tabular}

SD: standard deviation; CV: coefficient of variation.

parameter has the highest rate value (mean $=5.15)$. Thus, a high contamination risk of the aquifer is anticipated to emanate from this parameter. Moreover, the flow accumulation parameter $($ mean $=5.12)$ and hydraulic conductivity (mean = 4.24) have a moderate risk of contamination.

A high influence on the variation of the final vulnerability index is anticipated by the coefficient of variability of the hydraulic conductivity parameter $(\mathrm{CV}=$ $65.23 \%$ ), while moderate influence is anticipated by the variability of land-use $(\mathrm{CV}=51.89 \%)$ and flow accumulation $(\mathrm{CV}=46.21 \%)$ parameters. 


\subsection{Map Removal Sensitivity Analysis}

The summary of the map removal sensitivity calculated by removing one or more map layer(s) is presented in Table 9. The result indicates that the hydraulic conductivity and land-use parameters influence the final vulnerability index greatly according to their mean variation ( $V_{i}=4.08 \%$ and $2.44 \%$ ). This is as a result of the high weight assigned to these parameters ( $W_{T}=40$ and 30). Besides, it was observed that the influence on the final vulnerability index was moderate when the flow accumulation parameter was removed $\left(V_{i}=1.83 \%\right)$.

\subsection{Single Parameter Sensitivity Analysis}

The results obtained demonstrated some variations from the theoretical weights as presented in Table 10. The result reveals that the effective weight of parameter flow accumulation $\left(W_{\text {eff }}=30.00 \%\right)$ is greater than the theoretical weight $\left(W_{T}\right.$ $=34.90 \%$ ). Also, the flow accumulation parameter was considered the most effective parameter for this analysis. This result reaffirms the reason why this parameter is considered a critical parameter in this model. However, other parameters such as land-use and conductivity have their mean effective weight value $\left(W_{\text {eff }}=29.51 \%\right.$ and $\left.15.09 \%\right)$ to be less than the theoretical weight $\left(W_{T}=\right.$ $30.00 \%$ and $40.00 \%)$.

\subsection{Vulnerability Map Validation}

The relationship between various indexes of aquifer vulnerability and nitrate concentrations in wells are discussed in this section. The justification behind the selection of this chemical parameter was due to the improper use of fertilizers and manure from the agricultural sectors. This model, however, presumes that the contaminant has to migrate with water. Nitrates are generally very stable,

Table 9. Summary of map removal sensitivity.

\begin{tabular}{ccccc}
\hline \multirow{2}{*}{ Removed } & \multicolumn{3}{c}{$V_{i}(\%)$} \\
\cline { 2 - 4 } & Min. & Max. & Mean & SD \\
\hline fa & 0.45 & 3.92 & 1.83 & 0.20 \\
lan & 0.56 & 4.52 & 2.44 & 0.28 \\
\hline hyd & 1.34 & 6.82 & 4.08 & 0.53 \\
\hline
\end{tabular}

SD: standard deviation; $V_{i}$ : variation index; Min: minimum; Max: maximum.

Table 10. Summary of single-parameter sensitivity.

\begin{tabular}{|c|c|c|c|c|c|}
\hline \multirow{2}{*}{ Removed } & \multirow{2}{*}{$\frac{W_{T}}{(\%)}$} & \multicolumn{4}{|c|}{$W_{\text {eff }}(\%)$} \\
\hline & & Min & $\operatorname{Max}$ & Mean & SD \\
\hline fa & 30.00 & 0.00 & 73.54 & 34.90 & 9.42 \\
\hline lan & 30.00 & 0.00 & 36.10 & 29.51 & 7.55 \\
\hline hyd & 40.00 & 2.00 & 28.32 & 15.09 & 5.61 \\
\hline
\end{tabular}

SD: standard deviation; $W_{T}$ : theoretical weight; $W_{\text {eff. }}$ effective weight; Min: minimum; Max: maximum. 
dissolve quickly in water and can migrate several kilometres from their source fulfil this assumption. Consequently, production drilled wells from 30 separate locations were sampled and analysed for nitrate concentrations in a laboratory. The handheld Global Positioning System (GPS) Garmin etrex 20 was deployed to record the geographical locations of the sampled drilled wells.

\subsubsection{The Spatial Nitrate Concentration}

The laboratory assessment on the sampled wells revealed that the nitrate concentrations vary from $0.21 \mathrm{mg} / \mathrm{L}$ to $34.89 \mathrm{mg} / \mathrm{L}$ as presented in Figure 11. Table 11 presents a statistical summary of the sampling distribution. The acceptable threshold for nitrate concentration in drinking water is $50 \mathrm{mg} / \mathrm{L}$ according to the World Health Organization (WHO) guideline value. Also, many researchers have specifically limelight that nitrate concentrations greater than $10 \mathrm{mg} / \mathrm{L}$ in production wells suggest pollution from human sources and can lead to serious and fatal health consequences, such as methemoglobinemia (Sener et al., 2009; Adimalla et al., 2021; Emeka et al., 2021; Kühling et al., 2021; Tsagris \& Tzouvelekas, 2021).

Graphically, Figure 12 presents the nitrate concentrations of the sampled wells in the study area. A layer of the sampled wells was generated and overlayed on the intrinsic vulnerability map using ArcGIS. This was conducted to ascertain the number of wells with low, moderate and high nitrate concentrations falls within their corresponding vulnerability classes for validation purposes.

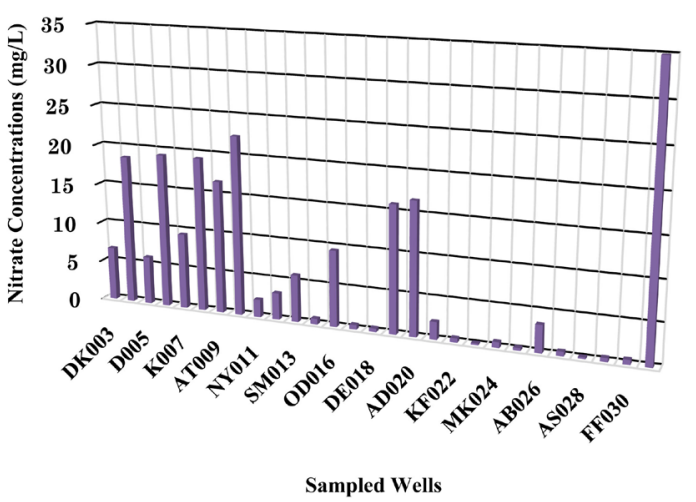

Figure 11. Nitrate concentrations in the sampled wells.

Table 11. Statistical summary of the sampling distribution.

\begin{tabular}{cc}
\hline No. of samples & 30 \\
Sum & 230.018 \\
Minimum & 0.208 \\
Maximum & 34.895 \\
Mean & 6.72838 \\
Standard Deviation & 7.32472 \\
Median & 3.726 \\
\hline
\end{tabular}




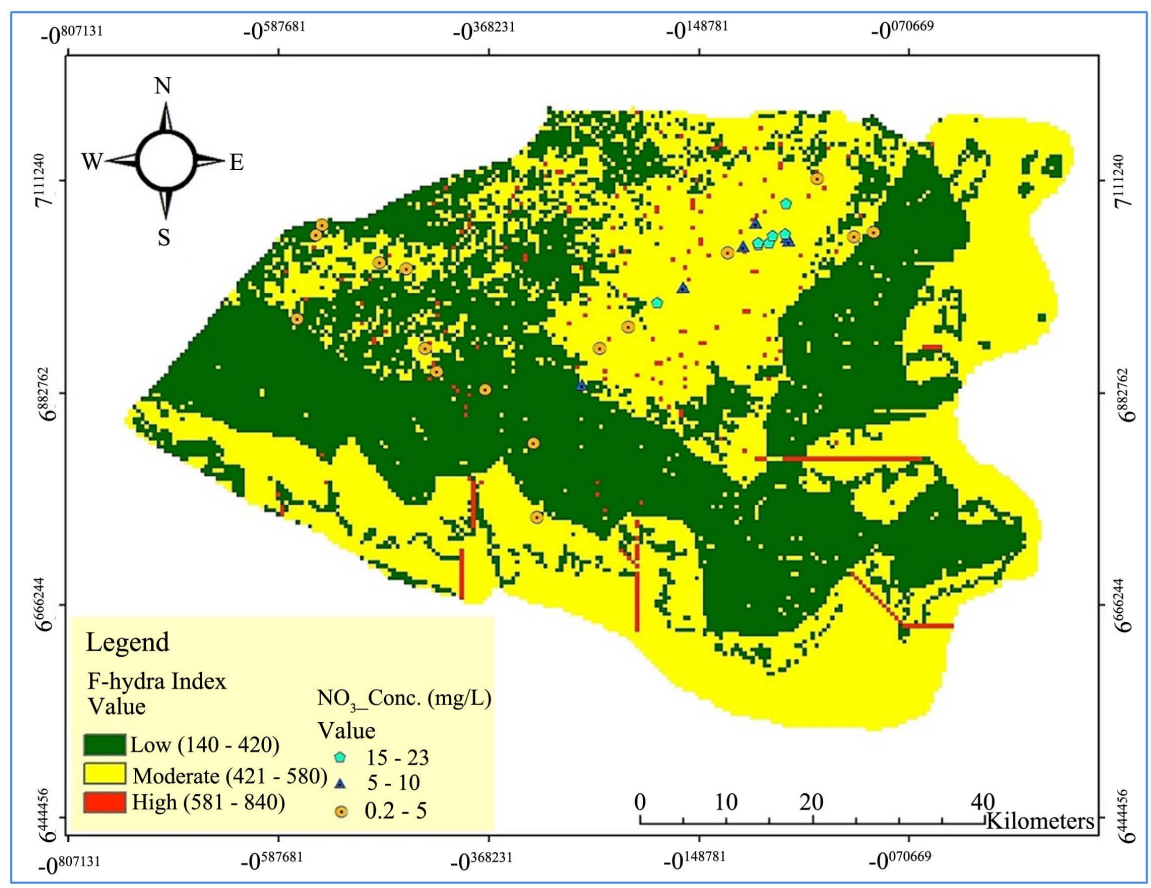

Figure 12. Superimposition of the nitrate concentrations in sampled wells on intrinsic vulnerability map.

\subsubsection{Regression Analysis}

The model was evaluated using one of the most widely used statistical tests in geohydrology. The coefficient of determination $\left(R^{2}\right)$ determines the correlation between the observed and simulated values. For this analysis, the F-hydra index was utilised as a replacement of the vulnerability map and plotted against the concentrations of on-ground nitrates. Awotwi et al. (2015), explicitly revealed that the coefficient of determination should be greater than 0.6 for a model to be accepted or approved.

According to Figure 13, it can be established that the concentration of nitrate was closely related to the vulnerability indexes. The correlation of coefficient was found to be $R^{2}=0.6792$, which is slightly above the acceptable threshold $\left(R^{2}=\right.$ $0.6)$ for any model validation. Nonetheless, the DRASTIC model exhibited a positive correlation with the coefficient of determination $\left(R^{2}\right)$ of 0.9006 which is far above the acceptable threshold and can predict with $90 \%$ accuracy (Agyare et al., 2017). Besides, the F-hydra model can only predict with $67 \%$ accuracy. Thus, the F-hydra proves an innovative way of evaluating aquifer vulnerability, however, the results also show that further validation is strongly recommended using more measured data.

\section{Conclusion}

Aquifer vulnerability assessment is essential for decision-makers to prepare, prioritize, and plan monitoring programs. Groundwater vulnerability can be assessed using several models. The DRASTIC model is the most widely known and applicable in most geological settings. The major setback with this model is that 


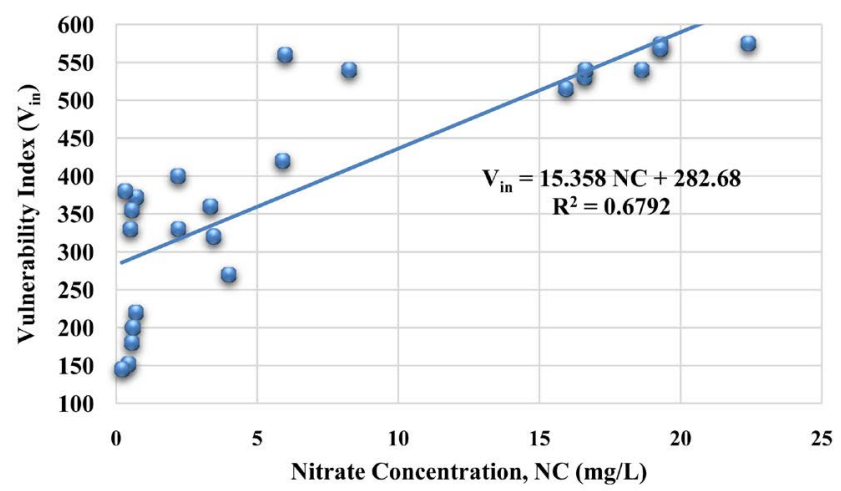

Figure 13. Correlation between nitrate concentration and F-hydra indexes.

it requires a lot of data, making it unsuitable for areas where is scarce. In this study, an attempt has been made to evaluate the vulnerability of aquifer systems to contamination in Afram Plains. This objective was achieved using the newly established F-hydra model. The study area is classified into 3 regions on the premise of a pollution index and both models show a close correlation to the mapped regions of low and moderate, except the high. Although, the index is still under development and may not be able to accurately predict the vulnerability of aquifers in specific environments. This model proved functional and tangible to the capabilities of the DRASTIC model. The following are the overall observation and conclusions arrived from this study.

A moderate vulnerability index implies that the aquifer is susceptible to several contaminants if only there is continuous leaching or discharging. The results reveal that the moderate vulnerability region covers $51.55 \%\left(2598.12 \mathrm{~km}^{2}\right)$ of the entire area. The high and low vulnerability regions cover a significant percentage of the area $1.13 \%\left(56.52 \mathrm{~km}^{2}\right)$ and $47.32 \%\left(2384.93 \mathrm{~km}^{2}\right)$, respectively.

The sensitivity analysis results reveal that the removal of the hydraulic conductivity and land-use influences a large variation in the final vulnerability index. This result confirms how these parameters are critical to this model.

The model was validated with nitrate concentrations in production drilled wells in the study area. This study has proven that nitrate concentration increases with increasing vulnerability index. A cross plot between the mean F-hydra vulnerability indexes and the on-ground nitrate concentration exhibited a relatively high correlation of $R^{2}=0.6792$ which is higher than the acceptable threshold for aquifer vulnerability modelling.

\section{Recommendation}

Groundwater is the primary water supply that provides more than half of the demand for water from the populace. An investigation into aquifer vulnerability ought to be an indispensable component of the country's pursuit of setting up a system for water policy development. Although the static water table is relatively shallow, the findings recommend that topmost priority should be given to new 
developments which are yet to be sited in the moderate vulnerable regions. The vulnerability map developed in this study could be used by policymakers, groundwater managers and planners as a general guide to vulnerability evaluation when implementing measures to protect this fragile resource.

The F-hydra model established an innovative way of evaluating the vulnerability of the aquifer to contamination in areas with limited data accessibility. However, this model requires a colossal advancement and validation to ascertain its applicability and dependability of the results, most especially a more standardised rating of the parameters.

\section{Acknowledgements}

Special thanks are given to A. Y. Modoc, Director of Afram Plains Development Organization (APDO), Komlavi Akpoti, Patrick Nyarko and Issoufou Ouedraogo, for providing a great deal of the data used in this study.

\section{Availability of Data and Materials}

The datasets used and analysed during this current study are included in this published article or available from the corresponding author on reasonable request.

\section{Authors Contributions}

AA: formal analysis, investigation, methodology, writing (original draft, review and editing). BB: methodology, writing (review and editing). AJ: methodology, writing (review and editing). AK: conceptualization, funding acquisition, investigation, methodology resources, writing (review and editing).

\section{Consent to Participate and Publish}

Not Applicable.

\section{Conflicts of Interest}

The authors declare no competing interests.

\section{References}

Adimalla, N., Qian, H., \& Tiwari, D. M. (2021). Groundwater Chemistry, Distribution and Potential Health Risk Appraisal of Nitrate Enriched Groundwater: A Case Study from the Semi-Urban Region of South India. Ecotoxicology and Environmental Safety, 207, Article ID: 111277. https://doi.org/10.1016/j.ecoenv.2020.111277

Agyare, A., Kwame, G., \& Kabo-bah, A. T. (2017). Assessing the Vulnerability of Aquifer Systems in the Volta River Basin: A Case-Study on Afram Plains, Ghana. Modeling Earth Systems and Environment, 3, 1141-1159.

https://doi.org/10.1007/s40808-017-0363-3

Akter, A., \& Ahmed, S. (2021). Modeling of Groundwater Level Changes in an Urban Area. Sustainable Water Resources Management, 7, 1-20.

https://doi.org/10.1007/s40899-020-00480-x 
Al Hallaq, A. H., \& Elaish, B. S. A. (2012). Assessment of Aquifer Vulnerability to Contamination in Khanyounis Governorate, Gaza Strip-Palestine, Using the DRASTIC Model within GIS Environment. Arabian Journal of Geosciences, 5, 833-847. https://doi.org/10.1007/s12517-011-0284-9

Al-Adamat, R. A. N., Foster, I. D. L., \& Baban, S. M. J. (2003). Groundwater Vulnerability and Risk Mapping for the Basaltic Aquifer of the Azraq Basin of Jordan Using GIS, Remote Sensing and DRASTIC. Applied Geography, 23, 303-324.

https://doi.org/10.1016/j.apgeog.2003.08.007

Aller, L., Bennett, T., Lehr, J. H., Petty, R. J., \& Hackett, G. (1987). DRASTIC: A Standardized Method for Evaluating Ground Water Pollution Potential Using Hydrogeologic Settings. NWWA/Epa-600/2-87-035, 455.

Anornu, G. K., Kabo-bah, A. T., \& Anim-Gyampo, M. (2012). Evaluation of Groundwater Vulnerability in the Densu River Basin of Ghana. American Journal of Human Ecology, 1, 79-86.

Aslam, R. A., Shrestha, S., \& Pandey, V. P. (2018). Groundwater Vulnerability to Climate Change: A Review of the Assessment Methodology. Science of the Total Environment, 612, 853-875. https://doi.org/10.1016/j.scitotenv.2017.08.237

Awotwi, A., Kumi, M., Jansson, P. E., Yeboah, F., \& Nti, I. K. (2015). Predicting Hydrological Response to Climate Change in the White Volta Catchment, West Africa. Journal of Earth Science \& Climatic Change, 6, 249.

https://doi.org/10.4172/2157-7617.1000249

Balaji, L., Saravanan, R., Saravanan, K., \& Sreemanthrarupini, N. A. (2021). Groundwater Vulnerability Mapping Using the Modified DRASTIC Model: The Metaheuristic Algorithm Approach. Environmental Monitoring and Assessment, 193, 1-19.

https://doi.org/10.1007/s10661-020-08787-0

Chakraei, I., Safavi, H. R., Dandy, G. C., \& Golmohammadi, M. H. (2021). Integrated Simulation-Optimization Framework for Water Allocation Based on Sustainability of Surface Water and Groundwater Resources. Journal of Water Resources Planning and Management, 147, Article ID: 5021001. https://doi.org/10.1061/(ASCE)WR.1943-5452.0001339

Chilton, J. (2006). Assessment of Aquifer Pollution Vulnerability and Susceptibility to the Impacts of Abstraction. In O. Schmoll, G. Howard, J. Chilton, \& I. Chorus (Eds.), Protecting Groundwater for Health: Managing the Quality of Drinking-Water Sources (pp. 199-241). World Health Organization.

Daly, D., Dassargues, A., Drew, D., Dunne, S., Goldscheider, N., Neale, S., Popescu, I. C., \& Zwahlen, F. (2002). Main Concepts of the "European Approach" to Karst-Groundwater Vulnerability Assessment and Mapping. Hydrogeology Journal, 10, 340-345. https://doi.org/10.1007/s10040-001-0185-1

Davies, J. (2002). Low Permeability Rocks in Sub-Saharan Africa: Visit to Ghana to Disseminate Project Results, 16-23 March 2002.

Doerfliger, N., Jeannin, Y.-P., \& Zwahlen, F. (1999). Water Vulnerability Assessment in Karst Environments: A New Method of Defining Protection Areas Using a Multi-Attribute Approach and GIS Tools (EPIK Method). Environmental Geology, 39, 165-176. https://doi.org/10.1007/s002540050446

Egbi, C. D., Anornu, G., Appiah-Adjei, E. K., Ganyaglo, S. Y., \& Dampare, S. B. (2019). Evaluation of Water Quality Using Hydrochemistry, Stable Isotopes, and Water Quality Indices in the Lower Volta River Basin of Ghana. Environment, Development and Sustainability, 21, 3033-3063. https://doi.org/10.1007/s10668-018-0180-5

Emeka, C., Nweke, B., Ihunwo, C. K., \& Nta, S. (2021). Assessment of Groundwater 
Quality in Close Proximity to Septic Tanks and Potential Impact on Health. European Journal of Environment and Earth Sciences, 2, 8-10. https://doi.org/10.24018/ejgeo.2021.2.1.104

Erostate, M., Huneau, F., Garel, E., Lehmann, M. F., Kuhn, T., Aquilina, L., Vergnaud-Ayraud, V., Labasque, T., Santoni, S., Robert, S., Provitolo, D., \& Pasqualini, V. (2018). Delayed Nitrate Dispersion within a Coastal Aquifer Provides Constraints on Land-Use Evolution and Nitrate Contamination in the Past. Science of the Total Environment, 644, 928-940. https://doi.org/10.1016/j.scitotenv.2018.06.375

European Commission COST Action 620 (2003). Vulnerability and Risk Mapping for the Protection of Carbonate (Karst) Aquifers: Scopes-Goals-Results. Luxembourg: European Commission, Directorate-General: Science, Research and Development.

Fatema, S. (2020). Vulnerability Assessment of the Coastal Aquifers in the Cox's Bazar Area, Bangladesh Using Hydrochemical Tools and the GALDIT Model. Ph.D. Thesis, Darmstadt: Technische Universität Darmstadt.

Foster, S. S. D. (1987). Fundamental Concepts in Aquifer Vulnerability, Pollution Risk and Protection Strategy. In W. Duijvenbooden, \& H. G. Waegeningh (Eds.), Vulnerability of Soil and Groundwater to Pollutants (pp. 69-86). The Hague: Proc Info.

Ghouili, N., Jarraya-Horriche, F., Hamzaoui-Azaza, F., Zaghrarni, M. F., Ribeiro, L., \& Zammouri, M. (2021). Groundwater Vulnerability Mapping Using the Susceptibility Index (SI) Method: Case Study of Takelsa Aquifer, Northeastern Tunisia. Journal of African Earth Sciences, 173, Article ID: 104035. https://doi.org/10.1016/j.jafrearsci.2020.104035

Gleeson, T., Moosdorf, N., Hartmann, J., \& van Beek, L. P. H. (2014). A Glimpse Beneath Earth's Surface: GLobal HYdrogeology MaPS (GLHYMPS) of Permeability and Porosity. Geophysical Research Letters, 41, 3891-3898. https://doi.org/10.1002/2014GL059856

Gogu, R. C., Hallet, V., \& Dassargues, A. (2003). Comparison of Aquifer Vulnerability Assessment Techniques. Application to the Néblon River Basin (Belgium). Environmental Geology, 44, 881-892. https://doi.org/10.1007/s00254-003-0842-X

Gogu, R., \& Dassargues, A. (2000). Current Trends and Future Challenges n Groundwater Vulnerability Assessment Using Overlay and Index Methods. Environmental Geology, 39, 549-559. https://doi.org/10.1007/s002540050466

Goldscheider, N., Klute, M., Sturm, S., \& Hötzl, H. (2000). The PI Method-A GIS-Based Approach to Mapping Groundwater Vulnerability with Special Consideration of Karst Aquifers. Zeitschrift für Angewandte Geologie, 46, 157-166.

Gumma, M. K., \& Pavelic, P. (2013). Mapping of Groundwater Potential Zones across Ghana Using Remote Sensing, Geographic Information Systems, and Spatial Modeling. Environmental Monitoring and Assessment, 185, 3561-3579.

https://doi.org/10.1007/s10661-012-2810-y

Hasiniaina, F., Zhou, J., \& Guoyi, L. (2010). Regional Assessment of Groundwater Vulnerability in Tamtsag Basin, Mongolia Using Drastic Model. Journal of American Science, 6, 65-78.

Hosseini, M., \& Saremi, A. (2018). Assessment and Estimating Groundwater Vulnerability to Pollution Using a Modified DRASTIC and GODS Models (Case Study: Malayer Plain of Iran). Civil Engineering Journal, 4, 433-442. https://doi.org/10.28991/cej-0309103

Jaunat, J., Garel, E., Huneau, F., Erostate, M., Santoni, S., Robert, S., Fox, D., \& Pasqualini, V. (2019). Combinations of Geoenvironmental Data Underline Coastal Aquifer Anthropogenic Nitrate Legacy through Groundwater Vulnerability Mapping 
Methods. Science of the Total Environment, 658, 1390-1403.

https://doi.org/10.1016/j.scitotenv.2018.12.249

Kabo-bah, A. T., Appiah-Sefah, G., Anornu, G. K., \& Boateng, K. (2014). F-Hydra Index for Evaluating Groundwater Vulnerability in Data Scarce Regions. Journal of Environment \& Ecology, 5, 1-14. https://doi.org/10.5296/jee.v5i1.5361

Krishna, R., Iqbal, J., Gorai, A. K., Pathak, G., Tuluri, F., \& Tchounwou, P. B. (2015). Groundwater Vulnerability to Pollution Mapping of Ranchi District Using GIS. Applied Water Science, 5, 345-358. https://doi.org/10.1007/s13201-014-0198-2

Kühling, I., Beiküfner, M., Vergara, M., \& Trautz, D. (2021). Effects of Adapted N-Fertilisation Strategies on Nitrate Leaching and Yield Performance of Arable Crops in North-Western Germany. Agronomy, 11, 64. https://doi.org/10.3390/agronomy11010064

Li, P., Zhang, C., Li, W., \& Li, Y. (2021). Groundwater Vulnerability Assessment of Pingtan Island in Fuzhou City, China, Based on DRASLI-QUE. Journal of Hydrologic Engineering, 26, Article ID: 5020050.

https://doi.org/10.1061/(ASCE)HE.1943-5584.0002030

Liggett, J. E., \& Talwar, S. (2009). Groundwater Vulnerability Assessments and Integrated Water Resource Management. Watershed Management Bulletin, 13, 18-29.

Lutz, A., Thomas, J. M., Pohll, G., \& Mckay, W. A. (2007). Groundwater Resource Sustainability in the Nabogo Basin of Ghana. Journal of African Earth Sciences, 49, 61-70. https://doi.org/10.1016/j.jafrearsci.2007.06.004

Lv, M., Ma, Z., \& Yuan, N. (2021). Attributing Terrestrial Water Storage Variations across China to Changes in Groundwater and Human Water Use. Journal of Hydrometeorology, 22, 3-21. https://doi.org/10.1175/JHM-D-20-0095.1

Margat, J. (1968). Contamination Vulnerability Mapping of Groundwater. Orleans : Bureau de Recherches Geologiques et Minieres.

Meran, G., Siehlow, M., \& von Hirschhausen, C. (2021). Integrated Water Resource Management: Principles and Applications. In The Economics of Water (pp. 23-121). Cham: Springer. https://doi.org/10.1007/978-3-030-48485-9 3

Moreno, L. J. A., Lemus, D. del S. Z., Rosero, J. L., Morales, D. M. A., Castaño, L. M. S., \& Cuervo, D. P. (2020). Evaluation of Aquifer Contamination Risk in Urban Expansion Areas as a Tool for the Integrated Management of Groundwater Resources. Case: Coffee Growing Region, Colombia. Groundwater for Sustainable Development, 10, Article ID: 100298. https://doi.org/10.1016/j.gsd.2019.100298

Mutiara, T., Kusratmoko, E., \& Marko, K. (2021). Spatial Quality of Shallow Groundwater in DAS Cijurey Regency of Majalengka, West Java. IOP Conference Series: Earth and Environmental Science, 623, Article ID: 012026. https://doi.org/10.1088/1755-1315/623/1/012026

Nageswara Rao, K., \& Narendra, K. (2006). Mapping and Evaluation of Urban Sprawling in the Mehadrigedda Watershed in Visakhapatnam Metropolitan Region Using Remote Sensing and GIS. Current Science, 91, 1552-1557.

Neukum, C., \& Azzam, R. (2009). Quantitative Assessment of Intrinsic Groundwater Vulnerability to Contamination Using Numerical Simulations. Science of the Total Environment, 408, 245-254. https://doi.org/10.1016/j.scitotenv.2009.09.046

Oke, S. A. (2015). Evaluation of the Vulnerability of Selected Aquifer Systems in the Eastern Dahomey Basin, South Western Nigeria. Bloemfontein: University of the Free State.

Oke, S. A., \& Vermeulen, D. (2020). Evaluation of the Comparison of Four Groundwater Vulnerability Methodologies. In A. J. Witkowski, S. Jakóbczyk-Karpierz, J. Czekaj, \& 
D. Grabala (Eds.), Groundwater Vulnerability and Pollution Risk Assessment,. London: CRC Press. https://doi.org/10.1201/9780367822927-13

Olorunfemi, M. O., Ojo, J. S., \& Akintunde, O. M. (1999). Hydro-Geophysical Evaluation of the Groundwater Potentials of the Akure Metropolis, Southwestern Nigeria. Journal of Mining and Geology, 35, 207-228.

Ouedraogo, I., Defourny, P., \& Vanclooster, M. (2016). Mapping the Groundwater Vulnerability for Pollution at the Pan African Scale. Science of the Total Environment, 544, 939-953. https://doi.org/10.1016/j.scitotenv.2015.11.135

Pelekanos, N., Nikolopoulos, D., \& Makropoulos, C. (2021). Simulation and Vulnerability Assessment of Water Distribution Networks under Deliberate Contamination Attacks. Urban Water Journal, 1-14. https://doi.org/10.1080/1573062X.2020.1864832

Pollicino, L. C., Masetti, M., Stevenazzi, S., Cristaldi, A., Righetti, C., \& Gorla, M. (2021). Multi-Aquifer Susceptibility Analyses for Supporting Groundwater Management in Urban Areas. Journal of Contaminant Hydrology, 238, Article ID: 103774. https://doi.org/10.1016/j.jconhyd.2021.103774

Rahman, A. (2008). A GIS Based DRASTIC Model for Assessing Groundwater Vulnerability in Shallow Aquifer in Aligarh, India. Applied Geography, 28, 32-53. https://doi.org/10.1016/j.apgeog.2007.07.008

Rani, N. N. V. S., Satyanarayana, A. N. V, Bhaskaran, P. K., Rice, L., \& Kantamaneni, K. (2021). Assessment of Groundwater Vulnerability Using Integrated Remote Sensing and GIS Techniques for the West Bengal Coast, India. Journal of Contaminant Hydrology, 238, Article ID: 103760. https://doi.org/10.1016/j.jconhyd.2020.103760

Robins, N. S., Chilton, P. J., \& Cobbing, J. E. (2007). Adapting Existing Experience with Aquifer Vulnerability and Groundwater Protection for Africa. Journal of African Earth Sciences, 47, 30-38. https://doi.org/10.1016/j.jafrearsci.2006.10.003

Rokhshad, A. M., Siuki, A. K., \& Yaghoobzadeh, M. (2021). Evaluation of a Machine-Based Learning Method to Estimate the Rate of Nitrate Penetration and Groundwater Contamination. Arabian Journal of Geosciences, 14, 1-11. https://doi.org/10.1007/s12517-020-06257-y

Samake, M., Tang, Z., Hlaing, W., Innocent, N., Kasereka, K., \& Balogun, W. O. (2011). Groundwater Vulnerability Assessment in Shallow Aquifer in Linfen Basin, Shanxi Province, China Using DRASTIC Model. Journal of Sustainable Development, 4, 53-71. https://doi.org/10.5539/jsd.v4n1p53

Sener, E., Sener, S., \& Davraz, A. (2009). Assessment of Aquifer Vulnerability Based on GIS and DRASTIC Methods: A Case Study of the Senirkent-Uluborlu Basin (Isparta, Turkey). Hydrogeology Journal, 17, 2023-2035. https://doi.org/10.1007/s10040-009-0497-0

Shen, D. (2021). Water Resource Allocation and Regulation in Yellow River Basin. In Water Resources Management of the People's Republic of China (pp. 291-306). Cham: Springer. https://doi.org/10.1007/978-3-030-61931-2 14

Shirazi, S. M. M., Imran, H. M. M., \& Akib, S. (2012). GIS-Based DRASTIC Method for Groundwater Vulnerability Assessment: A Review. Journal of Risk Research, 15, 991-1011. https://doi.org/10.1080/13669877.2012.686053

Shirazi, S. M., Imran, H. M., Akib, S., Yusop, Z., \& Harun, Z. B. (2013). Groundwater Vulnerability Assessment in the Melaka State of Malaysia Using DRASTIC and GIS Techniques. Environmental Earth Sciences, 70, 2293-2304. https://doi.org/10.1007/s12665-013-2360-9

Song, K., Ren, X., Mohamed, A. K., Liu, J., \& Wang, F. (2020). Research on Drinking-Groundwater Source Safety Management Based on Numerical Simulation. Scien- 
tific Reports, 10, 1-17. https://doi.org/10.1038/s41598-020-72520-7

Stempvoort, D., Van Ewert, L., \& Wassenaar, L. (1993). Aquifer Vulnerability Index: A Gis-Compatible Method for Groundwater Vulnerability Mapping. Canadian Water Resources Journal, 18, 25-37. https://doi.org/10.4296/cwrj1801025

Stournaras, G., Nicolaos, L., \& Katsanou, K. (2011). Groundwater Vulnerability Assessment in the Loussi Polje Area, N Peloponessus: The PRESK Method. In N. Lambrakis, G. Stournaras, \& K. Katsanou (Eds.), Advances in the Research of the Environment (Vol. 2, pp. 335-342). Berlin, Heidelberg: Springer. https://doi.org/10.1007/978-3-642-24076-8 39

Tsagris, M., \& Tzouvelekas, V. (2021). Nitrate Pollution and Efficiency Measurement in Intensive Farming Systems: A Parametric By-Production Technology Approach. Working Papers 2101, University of Crete, Department of Economics.

Tsoy, I. (2015). Groundwater Vulnerability Assessment for Railroad Construction in Stockholm, Sweden, Using Spatial Multi Criteria Analysis.

US EPA (Environmental Protection Agency) (1985). DRASTIC: A Standard System for Evaluating Groundwater Potential Using Hydrogeological Settings. Ada, Oklahoma WA/EPA Series.

van Beynen, P. E., Niedzielski, M. A., Bialkowska-Jelinska, E., Alsharif, K., \& Matusick, J. (2012). Comparative Study of Specific Groundwater Vulnerability of a Karst Aquifer in Central Florida. Applied Geography, 32, 868-877.

https://doi.org/10.1016/j.apgeog.2011.09.005

Vías, J. M., Andreo, B., Perles, M. J., Carrasco, F., Vadillo, I., \& Jiménez, P. (2006). Proposed Method for Groundwater Vulnerability Mapping in Carbonate (Karstic) Aquifers: The COP Method. Hydrogeology Journal, 14, 912-925.

https://doi.org/10.1007/s10040-006-0023-6

Vrba, J., \& Zaporozec, A. (1994). Guidebook on Mapping Groundwater Vulnerability (p. 16). Hannover: Heise. International Association of Hydrogeologists.

Wang, G., Xiao, C., Qi, Z., Liang, X., Meng, F., \& Sun, Y. (2021). Water Resource Carrying Capacity Based on Water Demand Prediction in Chang-Ji Economic Circle. Water, 13, 16. https://doi.org/10.3390/w13010016

Worrall, F., \& Kolpin, D. W. (2003). Direct Assessment of Groundwater Vulnerability from Single Observations of Multiple Contaminants. Water Resources Research, 39, 1345. https://doi.org/10.1029/2002WR001212

Xiang, X., Li, Q., Khan, S., \& Khalaf, O. I. (2021). Urban Water Resource Management for Sustainable Environment Planning Using Artificial Intelligence Techniques. Environmental Impact Assessment Review, 86, Article ID: 106515.

https://doi.org/10.1016/j.eiar.2020.106515 